\title{
La defensa de la doxa en la obra de Hannah Arendt
}

\author{
RICARDO GIBU SHIMABUKURO \\ Benemérita Universidad Autónoma de Puebla (México) \\ ricardogibu@gmail.com
}

\begin{abstract}
Resumen
Si la eliminación de la palabra y la persuasión determinan el origen de la violencia, ¿su restauración no podría abrir la posibilidad de la convivencia pacífica? La doxa, aquella forma de conocimiento que la filosofía desde sus orígenes ha desterrado al reino de lo ilusorio ¿no podría constituir el ámbito propicio del diálogo político en donde los interlocutores se abran a la comprensión del otro sin querer imponer una verdad absoluta? El objetivo de este trabajo será considerar el papel de la doxa en el pensamiento de Arendt, dentro de su proyecto de reinterpretar la relación entre la filosofía y la política.
\end{abstract}

Palabras clave: Filosofía política, doxa, totalitarismo, intersubjetividad.

\section{The defense of doxa in the work of Hannah Arendt}

\begin{abstract}
If the removal of dialogue and persuasion determine the origin of violence; could not their restoration open the possibility of peaceful coexistence? Doxa, that form of knowledge that philosophy, since its inception, has banished to the realm of illusion; might not be the enabling environment for political dialogue in which interlocutors are open to understanding each other without aiming to impose an absolute truth? The objective of this work will be to consider the role of doxa in the thought of Arendt, within her project to reinterpret the relationship between philosophy and politics.
\end{abstract}

Key words: Political philosophy, doxa, totalitarianism, intersubjectivity.

Doctor en Filosofía por la Pontificia Universidad Lateranense (Roma, Italia). En la actualidad es Profesor-Investigador de la Benemérita Universidad Autónoma de Puebla (México). Es miembro del Sistema Nacional de Investigadores de México (nivel I). Ha publicado Unicidad y relacionalidad de la persona. La antropología de Romano Guardini (2008), Actualidad hermenéutica de la prudencia (coord., junto con A. Xolocotzi, 2009) y Proximidad y subjetividad. La antropología filosófica de Emmanuel Lévinas (2011). Entre sus artículos recientes cabe mencionar "Redefinición de la ßov́ $\lambda \varepsilon \sigma ı \varsigma$ y de la $\pi \rho o ́ v \varepsilon \sigma ı \varsigma$ aristotélicas en la ética de santo Tomás de Aquino" (2010) y "Reflexiones éticas en torno a lo artificial" (2011). 
La afirmación de Arendt de no querer ser considerada una filósofa, sino una teórica política entraña una toma de posición sobre la filosofía que debe aclararse ${ }^{1}$. Más que la intención de abandonar la filosofía, detrás de esta afirmación está el deseo de redefinirla en orden a comprender aquello que los filósofos de profesión fueron incapaces de comprender en los acontecimientos de orden político y social que marcaron la historia del siglo pasado, sobre todo aquellos vinculados a los totalitarismos. El itinerario intelectual de Arendt se puede explicar a partir del deseo de cumplir con las exigencias postergadas por los filósofos respecto a categorías idóneas que permitan comprender lo acontecido. En el ámbito filosófico ello significaba la posibilidad de reinterpretar la relación entre vida contemplativa y vida activa, más precisamente, entre filosofía y política que, desde Platón, aparecía bajo la impronta de una mutua hostilidad. La indiferencia o el desprecio del filósofo respecto a lo público inaugura una forma de violencia que se manifiesta cuando «hacer el bien» significa para él imponer la verdad a los demás sin necesidad de diálogo ni persuasión, de discurso ni debate político.

Si la eliminación de la palabra y la persuasión determinan el origen de la violencia política, ¿su restauración no podría abrir la posibilidad de la convivencia pacífica? En ese sentido, la doxa, aquella forma de conocimiento que la filosofía desde sus orígenes ha desterrado al reino de lo ilusorio ¿no podría constituir el ámbito propicio del diálogo político en donde los interlocutores se abren a la comprensión del otro sin querer imponer una verdad absoluta? Mi objetivo en este trabajo será, precisamente, considerar el papel de la doxa en el pensamiento de Arendt, dentro de su proyecto de reinterpretar la relación entre la filosofía y la política. El trabajo se dividirá en tres partes: en la primera, expondré el giro hacia lo político en el pensamiento de Arendt; en segundo lugar, abordaré el rol de la doxa en el ámbito de lo político, y finalmente, analizaré las posibilidades de una nueva filosofía política expuesta en La Condición Humana (1958).

\footnotetext{
1 En una entrevista realizada en octubre de 1964 decía lo siguiente: «Yo no pertenezco al círculo de los filósofos. Mi profesión, si puede hablarse así, es la teoría política. No me siento en modo alguna una filósofa... mi opinión es que yo no soy filósofa. En mi opinión, me despedí definitivamente de la filosofía... Frente a la política el filósofo no tiene una postura neutral. ¡No desde Platón!... Hay una suerte de hostilidad a toda política en la mayoría de los filósofos, con muy pocas excepciones... 'no quiero participar en absoluto de esa hostilidad': quiero mirar a la política, por así decirlo, con ojos no enturbiados por la filosofía», H. ARENDT: «¿Qué queda? Queda la lengua materna», en ibíd., Ensayos de comprensión 1930-1954, Caparrós, Barcelona 2005, 18.
} 


\section{Ruptura con la tradición}

El reconocimiento de que la filosofía fue incapaz de comprender la singularidad del fenómeno político en el pasado siglo, no puede desligarse de la dimensión personal que este hecho asumió en la vida de Arendt cuando los nazis asumieron el poder en el año 1933. Ella lo plantea así: «el problema, el verdadero problema personal no fue lo que hicieron nuestros enemigos, sino lo que hicieron nuestros amigos... Yo vivía en un medio intelectual (...) y pude comprobar que la 'uniformización' se convertía, por decir, en regla entre los intelectuales; no así en otros medios (...) Dejé Alemania dominada por la idea —algo exagerada sin duda- de 'nunca más', nunca más meterme en historias intelectuales» ${ }^{2}$. La dimensión afectiva y personal de esta decisión está en una relación directa con las consecuencias intelectuales a las que Arendt llegó tras esta experiencia: el totalitarismo nos pone ante la exigencia de romper con las categorías político-filosóficas conocidas hasta ese momento para poder comprender un fenómeno inédito en la historia de la humanidad. La exigencia de esta ruptura no viene impuesta por una teoría sino por la novedad del hecho histórico que se quiere comprender. Los ejercicios de comprensión política que realiza Arendt en su libro Los orígenes del totalitarismo de 1951 son precisamente el intento de iluminar una situación histórica novedosa ante la cual las categorías filosóficas tradicionales se mostraban deficientes y opacas. Para Arendt el desconcierto y la desorientación imperantes eran la prueba de que la pretendida supremacía de la mirada filosófica sobre el pensamiento político había llegado a su fin. Ahora bien, ¿en qué consistía la novedad del totalitarismo?

En la segunda parte de Los orígenes del totalitarismo titulada El imperialismo, Arendt señala que el siglo veinte fue testigo de un fenómeno de masas sin precedentes en la historia de la humanidad: el de los apátridas. Se trata de un fenómeno anterior propiamente al de los gobiernos totalitarios, pero estrechamente vinculado a éste. Su surgimiento se remonta al final de la primera guerra mundial tras la disolución del imperio austro-húngaro y el establecimiento de los Estados bálticos, más precisamente, cuando millones de rusos, centenares de miles de armenios, alemanes (muchos de los cuales eran judíos), húngaros y españoles, quedaron fuera de su patria perdiendo la nacionalidad a causa de sus divergencias con los gobiernos de turno. Se trataba de un fenómeno de desnaturalización o desnacionalización en masa, de la pérdida de protección de los respectivos gobiernos de la que

Ibíd. 
no había precedentes y para la cual era necesario crear una legislación de minorías que buscara salvaguardar su estatus legal. Las dos soluciones para el problema del apátrida, la de la repatriación y la de la nacionalización, fueron un fracaso. La primera, porque ni el país de origen ni ningún otro aceptaban al apátrida. El hecho de ser «indeportables» se tradujo en su condición de indeseables y en su indefensión ante la fuerza de la policía local. Los campos de internamiento se convirtieron en el único sustituto del país inexistente del apátrida. Ésta fue la solución que dará más adelante Hitler: después de reducir a los judíos alemanes a condición de una minoría no reconocida, los recogió de todas partes para enviarles a los campos de exterminio. La otra solución, la de la nacionalización, también fue un fracaso porque los países que acogían a los apátridas se negaron a atender las masivas solicitudes para nacionalizarse e incluso llegaron a aprobar leyes de desnacionalización para aquellos que la habían conseguido anteriormente. Sin derecho a residencia ni a trabajo, el apátrida era una anomalía social para la que no existía propiamente una ley. El derecho a tener derecho reconocido por la Carta de los Derechos Humanos parecía ser el mejor argumento para proteger su situación vulnerable, sin embargo, en el plano de los hechos se volvía una atribución prácticamente inexistente debido a su carácter abstracto y universal. Los únicos beneficiarios de tales derechos, paradójicamente, eran los ciudadanos de los países más prósperos, aquellos reconocidos como tales no por su condición de seres humanos sino por contar con una nacionalidad en toda regla. Se dio la extraña situación en la que el apátrida, para poder ser reconocido por la ley tenía que transgredirla, es decir, tenía que cometer un acto ilegal. Sólo el delito le permitía recobrar algún tipo de igualdad al ser juzgado como a cualquier otro ciudadano. Visto así, la tragedia del apátrida no era tanto existir al margen de la ley, es decir, en la ilegalidad, sino que no haya leyes para él. Su tragedia no era el ser víctima de alguna opresión, sino el que nadie quería oprimirle; no era el estar censurado, sino que a nadie le interesaba su opinión. No tener un lugar en el mundo es ante todo carecer de un espacio en donde sus palabras y acciones sean reconocidas y vistas por los demás. Para Arendt esta situación no se había dado antes en la historia y no puede ser ni siquiera comparada a la de los esclavos de la polis. Éstos no estaban desposeídos de una comunidad en la medida que su trabajo era necesitado, utilizado y valorado por los ciudadanos. Un ser humano que ha perdido su lugar en una comunidad y, por tanto, su status político, sólo puede valorar aquellas cualidades propias de su esfera privada, aquello que la naturaleza le ha dado y que Aristóteles atribuye a la fortuna: raza, belleza, amistad, fortuna, fuerza, etc. Y cuando esas cualidades son las 
únicas que pueden hacer valer su derecho a ser reconocido pueden asumir una violencia inusitada que no admite ninguna oposición ni resistencia.

Así como los apátridas configuran un escenario inédito en la historia de la humanidad, también constituye un hecho sin precedentes el surgimiento de los gobiernos totalitarios. El totalitarismo rompe con toda forma de gobierno conocida hasta entonces al punto de no poder ser juzgado como una variante del gobierno tiránico o como una forma ilegal de autoridad. El dinamismo interno del gobierno totalitario se coloca por encima del bien y del mal, de lo justo y de lo injusto, de modo que toda ley positiva queda eliminada en beneficio de una ley identificada con el devenir de la Naturaleza y de la Historia de la que procederían todas las leyes positivas ${ }^{3}$. La eliminación de la ley, de aquello que para Cicerón hacía posible la existencia de un pueblo (consensus iuris), era el paso necesario para que el gobierno totalitario realizara la justicia en la Tierra, la producción de una Humanidad que encarnaba la ley. Las leyes propuestas por el totalitarismo no se presentan como realidades inmutables inscritas en la conciencia del hombre, sino como leyes de movimiento que, con carácter de necesidad, arrastran todo a su paso. Ante la fuerza natural de ese dinamismo no existe oposición ni política ni social que pueda hacerle frente. Por ello la realización de ese movimiento asume la forma del terror. Terror que tiene como objetivo, en primer lugar, permitir que la fuerza de la Naturaleza y de la Historia fluya sin obstáculos, esto es, destruya toda acción que pretenda inútil e ingenuamente detenerla; y en segundo lugar, fabricar una Humanidad plena a través del sacrificio de los individuos que no la favorecen. En este proceso, no hay otro principio ni otro final que aquellos que están ya contenidos en esta ley. Sin posibilidad de otro origen que no sea el que esta ley impone, forma parte intrínseca del gobierno totalitario suprimir la vida individual en favor de la especie, sacrificar la pluralidad en favor de la uniformidad porque es en el individuo, más precisamente, en su acción libre, donde podría surgir un punto de partida exterior al dinamismo omniabarcante de la Naturaleza y de la Historia. Los hombres, sustituidos por el Hombre, forman ahora un constructo de dimensión universal que destruye el espacio que hay entre ellos para fusionarlos en un «anillo de hierro» que hace imposible toda distinción. En un entorno semejante lo decisivo ya no será crear alguna convicción entre los individuos determinada en favor del agente político, sino sobre todo destruir la posibilidad de que se genere algún tipo de convicción sea el que fuere; destruir cualquier tipo de deliberación y reflexión que lleve a

H. ARENDT: Los orígenes del totalitarismo. Alianza, Madrid 1981, 684. 
alguna certeza ${ }^{4}$ y, por tanto, a alguna acción. Las convicciones quedan reemplazadas por las ideologías que proponen una idea de la historia cuyo devenir no admite ya lugar a ningún misterio. En efecto, el movimiento natural o histórico en el que se inserta el gobierno totalitario tiene como misión, y he allí la importancia del terror, destruir todo aquello que retrase su despliegue, esto es, la libertad y la fuente de donde ésta surge: el nacimiento ${ }^{5}$.

\section{La defensa de la doxa}

El fin de la tradición sellado con el régimen totalitario puso en evidencia la vaciedad de las categorías filosóficas y, por tanto, la incapacidad del hombre contemporáneo de comprender su mundo. El conflicto secular entre la filosofía y la política pasaba a un segundo plano respecto al estado de marginalidad e irrelevancia que ahora ambas compartían en un mundo marcado por la quiebra del sentido común. Arendt considera que una situación semejante exige el desarrollo de «una nueva filosofía política de la cual pudiese surgir una nueva ciencia de la política» ${ }^{6}$. La realización de tal posibilidad implica comprender el origen del conflicto entre la filosofía y la política con el fin de: (1) superar las contradicciones y equívocos allí presentes y (2) alcanzar una mirada prospectiva para un trabajo en común en orden a la configuración de una sociedad plural. Son varios los trabajos en los que Arendt ofrece una interpretación sugerente de esta relación y posibilidades novedosas para una reflexión filosófica en el contexto político actual. Destacamos principalmente dos: Filosofía y Política de $1954^{7}$ y Algunas cuestiones de filosofía moral de 1965-1966.

La hostilidad de la filosofía hacia la política tiene como precedente el antiguo prejuicio de los ciudadanos de la polis contra los sabios (sophoi) expresado en aquella famosa anécdota, narrada tanto por Platón como

4 Ibíd., 692.

5 «(...) el terror como siervo obediente del movimiento histórico o natural, tiene que eliminar del proceso no sólo la libertad en cualquier sentido específico, sino la misma fuente de la libertad que procede del hecho del nacimiento del hombre y reside en su capacidad de lograr un nuevo comienzo», ibíd.., 690.

6 H. ARENDT: La promesa de la política. Paidós, Barcelona 2008, 75.

7 Publicado originalmente como "Philosophy and Politics", Social Research, 57/1 (1990), 73-103. Incluido también, bajo el título "Sócrates", en el libro La promesa de la política.

8 Publicado en el libro de H. AREndT: Responsabilidad y juicio. Paidós, Barcelona 2007. Jerome Kohn, editor del libro, señala que este trabajo recoge el conjunto de lecciones que Arendt impartió en la New School for Social Research en 1965 y 1966. 
Aristóteles ${ }^{9}$, de la joven de Tracia que se burlaba de Tales al verle caer en un pozo cuando observaba los astros en el cielo ${ }^{10}$. Si el sophos no sabe lo que es bueno para sí, menos puede saber lo que es bueno para la polis. Esta mirada despectiva no pasó a mayores mientras los filósofos asumían sin problemas su marginación social por parte de aquellos que los veían como seres desconectados de los asuntos de la vida cotidiana. El primer filósofo que quiso traspasar esta frontera trazada por la polis fue Sócrates. Sería un error, sin embargo, pensar que este traspasar socrático supone una confrontación de los filósofos contra los ciudadanos. Para Arendt esta posición de confrontación es la que representa más bien Platón. La muerte de Sócrates significó para su discípulo la confirmación de que el camino elegido, esto es, la exposición de la verdad a la crítica de sus interlocutores, había sido erróneo. La verdad expuesta a través de un discurso persuasivo entrañaba el riesgo de quedar reducida a una opinión entre opiniones, de quebrarse en su propia fragilidad y vulnerabilidad, tal como la sentencia contra Sócrates lo confirmó. Había que trabajar en función de una verdad liberada de este riesgo. La teoría de las ideas de Platón busca responder a la fragilidad y a la mutabilidad de la opinión puesto que la verdad de lo ideal no está en medio de los hombres, sino por encima de ellos. A pesar del carácter trascendente y, por tanto, apolítico de las ideas, Platón se resistía a aceptar el rol irrelevante y marginal al que la polis le destinaba. La primacía otorgada a la idea del bien respecto a las demás ideas buscaba revertir esta situación ${ }^{11}$. En efecto, si lo que debe regir la ciudad no es aquello que puede resultar bueno en una determinada situación, sino aquello que siempre es bueno, el gobierno de la ciudad debe estar en manos del filósofo pues sólo él está en relación con las realidades eternas. En un gobierno semejante, el diálogo y la persuasión dejan su lugar al mandato del legislador y a la obediencia de los ciudadanos.

Si bien Platón considera la dialegesthai como el discurso propiamente filosófico, ella será concebida en oposición a la persuasión y a la retórica. La dialéctica platónica no apunta al descubrimiento de la verdad junto con otros, sino a la mostración de una verdad que ya se conoce previamente. Por ello resulta paradójico que en los diálogos platónicos no sea el diálogo el medio que permite al filósofo acceder a la verdad,

9 Cfr. Platón: Teeteto, 174 e y ARIstóteles: Política, 1259 a 8-19.

10 H. ARENDT: La promesa de la política, 46.

11 «Únicamente si el reino de las ideas estaba iluminado por la idea del bien podía Platón hacer uso de las ideas para fines políticos», H. ARENDT: La promesa de la política, 49. 
sino la visión de la mente, la contemplación (theoría $)^{12}$. Persuadir significa para Platón «imponer la opinión propia a las opiniones de los demás» ${ }^{13}$, imponer la verdad de lo que se ha contemplado a través de un diálogo que en realidad no es tal. Prueba de ello es el recurso a los mitos al final de los diálogos políticos (con excepción de Las Leyes) que no tienen otro objetivo que suscitar el temor de los oyentes con imágenes sobre los sufrimientos de las almas, derivados de su mal comportamiento en esta vida. Si consideramos que el inicio de la filosofía coincide con la experiencia muda del thaumadzein, no nos debe resultar extraño que el quehacer filosófico se realice a partir de una contemplación caracterizada por su desvinculación con los demás hombres y por la ausencia de palabras $^{14}$. Esta posición no es sólo característica de Platón, sino también de Aristóteles para quien «la verdad última está más allá de las palabras. En la terminología aristotélica — señala Arendt— el recipiente humano es el nous, el espíritu, cuyo contenido no posee logos» ${ }^{15}$.

La confianza de Sócrates en la palabra hablada, en el razonamiento y en la persuasión como forma de alcanzar la verdad, muestra una idea del filosofar muy alejada a aquella guiada y dominada por la contemplación. En tal sentido, Arendt rechaza la interpretación tradicional que vincula la tríada Sócrates-Platón-Aristóteles con una filosofía cuyo fin es el theorein. Es posible que esta posición se originara como réplica a la idea que Heidegger exponía en el curso sobre El Sofista de Platón —al que la propia Arendt asistió- en el invierno de 1924-25 en Marburgo; idea según la cual Sócrates, Platón y Aristóteles habían sido los fundadores de la filosofía científica ${ }^{16}$. El carácter científico del filosofar permitía reivindicar una manera de existir orientada al descubrimiento de la realidad a través

12 «No mediante el discurso, sino contemplando esas Formas, visibles a los ojos de la mente, el filósofo entra en conocimiento de la Verdad, y mediante su alma, que es invisible e imperecedera -a diferencia del cuerpo (...)-, participa de la Verdad invisible, imperecedera, inmutable. Es decir, participa de ella viéndola y poseyéndola, no mediante el razonamiento y la argumentación», H. ARENDT: "Algunas cuestiones de filosofía moral", 104.

13 Ibíd., 51.

14 «La experiencia del filósofo sobre lo eterno, que para Platón era arheton («indecible») y aneu logou («sin palabra») para Aristóteles y que posteriormente fue conceptualizada en el paradójico nunc stans, sólo se da al margen de los asuntos humanos y de la pluralidad de hombres, como sabemos por el mito de la caverna en la República de Platón, habiéndose liberado de las trabas que le ataban a sus compañeros, abandona la caverna en perfecta «singularidad», por decirlo así, ni acompañado ni seguido por nadie», H. ARENDT: La condición bumana. Paidós, Buenos Aires 2009, 32.

15 H. ARENDT: La promesa de la política, 70.

16 M. Heidegger: Platon: Le Sophiste. Gallimard, Paris 2001, 222. 
de la comprensión originaria del ente (theorein $)^{17}$. Según Arendt, esta interpretación, si bien puede mantenerse en relación a los dos últimos, yerra en relación al primero ${ }^{18}$. Para Sócrates el filosofar no puede tener un fin fuera del ámbito político y, por tanto, no puede comprenderse como una theoría. Lo que él busca como filósofo es crear un mundo común, esto es, una comunidad. Esta realidad política sólo puede surgir a partir de lazos de amistad entre la ciudadanía ateniense dominada por el espíritu agonal y competitivo. La amistad, lejos de generar un proceso de homogenización, hace posible que seres humanos distintos sean compañeros en un mundo común bajo un régimen de igualdad. Sólo el amigo es capaz de crear un diálogo auténtico en el que se busca comprender la verdad contenida en la opinión del otro, sin imponer una verdad ya poseída. «El amigo comprende cómo y bajo qué articulación específica el mundo común se le presenta al otro, quien como persona permanece siempre desigual o distinto» ${ }^{19}$. El modo particular como el mundo se revela a cada quien, la comprensión del mundo «tal como se me presenta a mí» es lo que Sócrates entiende por doxa. No se trata de aquello que Aristóteles entiende como eikos, es decir, lo probable o lo verosímil; tampoco de una comprensión arbitraria o fantasiosa. Para comprender el sentido de la doxa al interior del discurso socrático es preciso vincularlo a su acepción no muy conocida de fama y de esplendor. En efecto, sólo puede haber doxa en la esfera pública, allí donde el ciudadano es capaz de mostrarse, esto es, ser visto y oído por los demás. Es precisamente en ese ámbito, no en la privacidad del hogar, donde el hombre podía asegurar su inmortalidad a través de la grandeza manifiesta de sus palabras y sus acciones, pero sobre todo, a través del reconocimiento de tal grandeza por parte de los demás ciudadanos.

Puesto que no hay un conocimiento a priori de la doxa ni una relación de superioridad del filósofo respecto al ciudadano, Sócrates debe empezar con preguntas. Las preguntas revelan que la intención socrática no es educar a los ciudadanos o gobernarles en función de una verdad

17 Ibíd.

18 Cabe indicar que para Heidegger también hay una distancia entre Sócrates y Platón. La oposición radical entre doxa y theoría fue obra principalmente de Platón y no de Sócrates. Fue Platón quien, injustificadamente, hizo de los sofistas los «representantes de algunos sistemas filosóficos determinados». Para el filósofo de Messkirch el nacimiento de la «filosofía como ciencia» jamás se identificó con un movimiento de oposición a ninguna doctrina ni escuela, menos aún a la sofística que «no ha tenido jamás el cuidado de tratar cuestiones científicas respecto a las cosas mismas». En efecto, «se hace de los sofistas los defensores de un escepticismo, relativismo, subjetivismo, entre otros apelativos. Pero una concepción semejante es insostenible», Ibíd., 208.

19 H. ARENDT: La promesa de la política, 54. 
absoluta ya poseída, sino ser un «tábano» capaz de aguijonear a sus amigos, esto es, capaz de sacar a la luz, mediante la mayéutica (el arte de la partera), la verdad presente en su doxa. En la medida que nadie conoce de modo inmediato la verdad inherente a su propia opinión, se hace precisa la auténtica dialegesthai para que tal verdad vaya apareciendo ante uno mismo. Esta dialéctica, por tanto, no busca destruir la doxa, sino revelar la validez que ella misma entraña. La verdad sólo puede manifestarse mediante el conocimiento de la realidad tal como se me aparece a mí. Una verdad entendida en términos absolutos y universales, desconectada y trascendente a la existencia del hombre singular, no está al alcance de los mortales. El «conócete a ti mismo» del templo de Delfos, es un recordatorio para Sócrates de que no tenemos la verdad acerca de todo y de que no podemos conocer la verdad del otro sino a través de la pregunta.

El hecho de que existan tantas opiniones como hombres existen, no pone en riesgo el elemento común del mundo (koinon) al que éstos pertenecen. Tal elemento queda asegurado en el hecho de que, a pesar de las diferencias, «tanto tú como yo somos humanos», esto es, vivimos en el modo del discurso ${ }^{20}$. Compartir la posibilidad de razonar y de dialogar es lo que permite a los hombres participar de un mundo común y liberarse del solipsismo. La única condición para la realización de esta posibilidad es estar de acuerdo consigo mismo, es decir, evitar la contradicción. El descubrimiento de la contradicción permite llegar a un aspecto de la realidad humana que marca el punto de quiebre de Sócrates respecto a la tradición filosófica posterior. Si bien fue Aristóteles el que fundó la lógica occidental sobre el principio de contradicción, fue Sócrates el que descubrió por vez primera este principio en el ámbito de la política y de la ética. En el diálogo Gorgias encontramos estas palabras de Sócrates: «(es mejor) que muchos hombres no estén de acuerdo conmigo y me contradigan, antes de que yo, que no soy más que uno, esté en desacuerdo conmigo mismo y me contradiga» ${ }^{21}$. El temor a la contradicción aparece aquí no sólo como un temor a una equivocación lógica, sino el temor a estar en desacuerdo conmigo mismo, a convivir con alguien que me podría resultar insoportable y del cual no habría posibilidad de distanciarse porque coincide con mi propia existencia. En otras palabras, caer en la contradicción significaría elegir la división, aceptar como modo de vida el conflicto entre dos voces en permanente pugna al interior del propio ser: la de la razón y la del sinsentido. Si la voz de la razón me prohíbe quitar la vida a alguien, no es por la

20 Ibíd., 52.

21 Platón: Gorgias 472c. 
existencia de testigos potenciales, sino porque no aceptaría bajo ningún concepto vivir junto a un asesino. «Al cometer asesinato estarías en compañía de un asesino para el resto de tu vida» ${ }^{22}$.

El temor a la contradicción revela un hecho antropológico importante: que, aun estando solo, estoy en una relación de diálogo conmigo mismo, lo cual significa que si bien soy uno me muestro como si fuera dos. La condición antropológica del «dos-en-uno», en expresión de Arendt, indica que la primera sede de la aparición y de la pluralidad no es la esfera pública, sino la esfera de la propia subjetividad. Sócrates fue consciente del rol político que tenía el aparecer ante uno mismo. Su enseñanza podría resumirse en esta frase: «aparece ante ti mismo tal y como te gustaría aparecer ante los demás» ${ }^{23}$. Lo políticamente relevante de este modo de aparecer ante sí es que a través de ella testifico sobre mi propia existencia, sobre mi responsabilidad con los demás, sobre mis posibilidades futuras. En tal sentido, toda pretensión de huir de la pluralidad por parte del filósofo se torna, ante el hecho del diálogo y la aparición ante uno mismo, algo imposible. Para Arendt esta imposibilidad tendrá consecuencias importantes en la definición tradicional de la filosofía y también en el modo de comprender la relación entre filosofía y política. En efecto, el origen de la filosofía se ha vinculado, desde Platón y Aristóteles, con el asombro del filósofo ante aquello que existe; un asombro caracterizado por el aislamiento y la ausencia de palabras. En esta conmoción contemplativa el filósofo se enfrenta solitariamente a todo el universo, en una situación cercana a la que se presentará en el momento de su muerte. El carácter apolítico de esta experiencia se manifiesta en la universalidad y la indeterminación de la realidad contemplada que impide la asunción de cualquier doxa. Poseer una doxa significaría desde esta perspectiva asumir una forma de vida sellada por la volatilidad y mutabilidad. Por ello, cuando el filósofo recupera la palabra, se expresa no a través de opiniones sino a través de preguntas últimas (¿qué es el ser?, ¿cuál es el sentido de la existencia?, ¿qué es la muerte?) desligadas de respuestas inmediatas y singulares.

Para Arendt la oposición theoría-doxa mantenida tradicionalmente por la filosofía es una interpretación que no se sigue necesariamente del thaumadzein. Si la posibilidad de aparecer y de dialogar con uno mismo constituye un hecho ineludible del ser humano, el asombro filosófico no puede significar un hecho apolítico en sí mismo ni una ruptura con la pluralidad. La distinción que realiza Arendt entre soledad y solitud, permite una nueva comprensión del thaumadzein. Si la soledad es aquel estado de

22 H. ARENDT: La promesa de la política, 59.

23 Ibíd., 60. 
total abandono en el que ni siquiera soy capaz de hacerme compañía, es decir, en el que postergo el diálogo conmigo mismo, la solitud es el vivir conmigo mismo y el juzgar por mí mismo ${ }^{24}$. «La solitud —afirma Arendt- significa que, aunque solo, estoy junto con alguien (esto es, yo mismo). Significa que soy dos-en-uno» ${ }^{25}$. Las primeras palabras formuladas por Sócrates tras el thaumadzzein; aquel asombro que según Platón lo dejaba inmovilizado, transportado como en un rapto, con la mirada perdida, sin capacidad de ver y oír nada, se expresaba así: «sólo sé que nada sé». Este no saber socrático lejos de producir una ruptura con la polis significaba el punto de partida de la inserción del filósofo en el ámbito de la pluralidad. Para Arendt, el «sólo sé que no sé nada» de Sócrates significa lo siguiente: «sé que no tengo las verdades para todos; no puedo conocer la verdad del otro sino preguntándole y, así, familiarizarme con su doxa, que se le revela de un modo distinto al de todos los demás» ${ }^{26}$. La posibilidad de una nueva filosofía política supone la comprensión de un thaumadzein intrínsecamente vinculado con el mundo de los hombres; la comprensión de que el milagro de la pluralidad, de las distintas formas de ver la realidad en el espacio de un mundo común, es la razón más alta por la que el filósofo puede sorprenderse $e^{27}$.

\section{La posibilidad de una nueva filosofía política}

La condición bumana de 1958 constituye una de las más importantes propuestas de Arendt en relación a la nueva filosofía política que cuatro años antes había anticipado en su trabajo Filosofía y Política. El filosofar no debe conducir necesariamente, como en Platón, a un alejamiento de la polis ni al rechazo del mundo común manifestado a través de la doxa. Como ya hemos visto, la presencia de la pluralidad y del espacio de aparición en el propio sujeto permitirá a Arendt considerar la dimensión

24 H. ARENDT: "Algunas cuestiones de filosofía moral”, 112.

25 Ibíd., 113.

26 H. ARENDT: La promesa de la politica, 57.

27 «Si los filósofos - afirma Arendt-, a pesar de su necesario extrañamiento respecto de la vida diaria de los asuntos humanos, llegasen alguna vez a una verdadera filosofía política, tendrían que hacer de la pluralidad del hombre, de la cual surge todo el espacio de asuntos humanos - en su grandeza y en su miseria- el objeto de su thaumadzein. Hablando en términos bíblicos, tendrían que aceptar - tal y como aceptan en mudo asombro el milagro del universo, del hombre y del ser- el milagro de que Dios no creó al Hombre, sino que 'los creó macho y hembra'. Tendrían que aceptar con algo más que resignación ante la debilidad humana el hecho de que 'no es bueno para el hombre estar solo’», Ibíd., 75. 
política en el origen mismo de la filosofía y en su ulterior despliegue a través del preguntar. Las categorías filosóficas tradicionales consideradas en términos de inmutabilidad y absolutez, dejarán abierto el camino a categorías surgidas dentro de «las siempre cambiantes potencialidades del sí mismo junto al cual vivo» ${ }^{28}$. A modo de ejercicios de comprensión, analizaremos la novedad semántica en cuatro categorías expuestas en La condición bumana: igualdad y pluralidad, libertad y natalidad. Además de mostrar las posibilidades de una reflexión filosófica en el ámbito político, el análisis de estas categorías permitirá ver, por un lado, el modo cómo la filosofía y la política se reconcilian en la comprensión del mundo en el que vivimos, y, por otro, que la intención de Arendt de distanciarse de la filosofía debe entenderse en verdad como una exigencia de redefinirla.

\subsection{Igualdad y pluralidad}

Cuando la igualdad ya no puede ser justificada en virtud de un Dios Creador ni de una cualidad intrínseca al ser humano, cuando ella es comprendida como un hecho mundano en sí carente de algún fundamento trascendente, se abren dos posibilidades: la primera, confundir la igualdad con una cualidad innata del individuo el cual será considerado «normal» si es como los demás y «anormal» si es diferente a ellos. Es precisamente lo que sucedió tanto con la marginación de los apátridas como con la eliminación de los sospechosos en los gobiernos totalitarios. En ambos casos quienes perdieron las atribuciones que la ley les reconocía, perdieron al mismo tiempo las cualidades que les permitían ser tratados como semejantes o iguales. La segunda posibilidad, aquella que Arendt propone en este libro, es configurar un espacio político en donde los hombres, desiguales por naturaleza, tienen derechos iguales.

Arendt parte del reconocimiento del carácter mundano de la igualdad y de los derechos humanos. La igualdad no es un don de la naturaleza, no es algo que hemos recibido por el hecho de existir, más bien llegamos a ser iguales como miembros de una comunidad gracias a la decisión de concedernos unos a otros los mismos derechos ${ }^{29}$. Más que de una igualdad natural, que coincidiría propiamente con la identidad de la especie, Arendt habla de una igualdad política que se configura en el plano de la acción. Para explicitar la naturaleza de ésta, distingue las formas no políticas del obrar humano: la labor y el trabajo. La labor es la actividad vinculada al proceso biológico del cuerpo humano y a sus necesidades vitales. El trabajo es la actividad correspondiente a la

\footnotetext{
28 Ibíd., 60.

29 H. ARENDT: El origen del totalitarismo, 251.
} 
dimensión no natural de la existencia a través de la cual el hombre se procura un mundo artificial de cosas producidas. Ninguna de estas actividades implica la existencia de las demás personas para su despliegue. El mantenimiento de la existencia a nivel biológico así como la producción de realidades artificiales pueden realizarse en soledad. A diferencia de estas actividades, la acción humana que configura la igualdad implica necesariamente la posibilidad de aparecer ante los demás. Los seres humanos somos iguales en la medida que cada uno se hace visible y audible al otro a través de sus acciones (praxis) y de sus palabras. No se trata de la igualdad que impone el hecho biológico de la muerte, tampoco de la igualdad ante Dios. En ambos casos la igualdad se da en el aislamiento y la soledad, en una situación donde no hace falta la comunicación ni la presencia de los otros. Arendt se refiere a una igualdad entre pares, entre desiguales, capaces de distinguirse entre sí y de aparecer ante el otro a través de sus palabras y acciones. «Si los hombres no fueran iguales - afirma Arendt-, no podrían entenderse (...) Si los hombres no fueran distintos, es decir, cada ser humano diferenciado de cualquier otro que exista, haya existido o existirá, no necesitarían el discurso ni la acción para entenderse. Signos y sonidos bastarían para comunicar las necesidades inmediatas e idénticas $\rangle^{30}$. Arendt tiene como referente la polis griega donde se incentivaba el espíritu competitivo, «agonal». Lejos de promover la uniformidad de conducta, la polis impulsaba a que el individuo se distinga de los demás, y demostrara con sus acciones y palabras que era el mejor. Es precisamente en este espacio político donde el hombre puede mostrar quién es ${ }^{31}$.

Esta igualdad entre desiguales, este poder «vivir como ser distinto y único entre iguales $\rangle^{32}$, esta pluralidad, es la condición básica de la esfera política gracias a la cual queda asegurada la realidad de las acciones humanas. En efecto, la presencia constante de otros que ven la acción de una persona da testimonio de la realidad y consistencia de esa acción ${ }^{33}$. Si el ser humano cobra realidad cuando es visto y oído por sus semejantes, el estar privado de esta posibilidad, el estar privado de una relación con los otros a través de un mundo común, significa para este sujeto algo muy cercano a la muerte. Gracias a la pluralidad los hombres son capaces de insertarse en el mundo propiamente humano y de alcanzar una nueva forma de existencia, al modo de un segundo nacimiento. Esta nueva

\footnotetext{
30 Ibíd., 200.

31 H. ARENDT: La condición bumana, 52.

32 Ibíd., 201.

33 Ibíd., 108.
} 
inserción ya no es aquella que nace en el intervalo estable entre cosas y seres humanos por obra del trabajo, sino en el intervalo intangible generado entre los seres humanos a través de la acción. Afirma Arendt: «Este segundo, subjetivo en medio de no es tangible, puesto que no hay objetos tangibles en los que pueda solidificarse; el proceso de actuar y hablar puede no dejar tras sí resultados y productos finales. Sin embargo, a pesar de su intangibilidad, este en medio de no es menos real que el mundo de cosas que visiblemente tenemos en común» ${ }^{34}$. La pluralidad también asegura que las posibilidades individuales queden claramente delimitadas en la esfera pública por el poder de los demás. Si ella se eliminase se acrecentaría ilimitadamente la fuerza de los individuos al punto de poner en peligro la igualdad de los hombres, la diversidad de perspectivas y el espacio común.

\subsection{Libertad y natalidad}

Si el totalitarismo constituye una ruptura con la tradición es porque los hechos históricos no son resultado de un conjunto de ideas y valores del que él mismo es un simple caso o ejemplo, sino acontecimientos que tienen como origen un elemento imprevisible e incalculable: la libertad humana. La confirmación de que la libertad trasciende toda tradición y, por tanto, toda forma de gobierno es también la clave que permite a Arendt criticar la lógica totalitaria. A diferencia de la labor en donde reina la necesidad de lo biológico, a través de la acción se abre el espacio de la libertad. En tal sentido, ser libre sólo puede comprenderse en la esfera política, allí donde el hombre deja de estar sometido a la necesidad de la vida y a la autoridad de alguien, y es capaz aparecer ante los demás en su singularidad e irrepetibilidad. La diferencia entre la necesidad y la libertad está precisamente en la diferencia que establecían los griegos entre la esfera privada y la esfera pública, entre el ámbito de lo natural y el ámbito de lo político. El hombre es libre en el momento que abandona la casa y la familia, precisamente cuando abandona la desigualdad que rige en un hogar (la relación padre-hijo es esencialmente vertical) e ingresa en la esfera política donde todos los hombres son iguales. Arendt llama también a la esfera política, el «espacio de aparición», es decir, «el espacio donde yo aparezco ante otros como otros aparecen ante mí, donde los hombres no existen meramente como otras cosas vivas o inanimadas, sino que hacen su aparición de manera

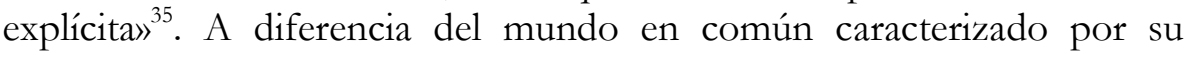

\footnotetext{
$34 \quad$ Ibíd., 207.

35 Ibíd., 221.
} 
estabilidad, el espacio de aparición se caracteriza por su potencialidad y contingencia, esto es, por su dependencia respecto no sólo a la existencia de los hombres sino sobre todo a sus acciones ${ }^{36}$. Poder hablar y actuar es una atribución de seres libres, por tanto, el espacio de aparición existirá en la medida en que exista la decisión de ejercer esa posibilidad.

Si la libertad aparece con la acción queda claro que no es un atributo natural del hombre, sino una realidad que supone la pluralidad y, por tanto, la esfera política. Con la palabra y la acción el hombre se inserta en el mundo humano. Ahora bien, nadie ni nada obliga al hombre a insertarse en el mundo ni a aparecer ante los demás a través de sus acciones. Cada vez que el hombre decide actuar se presenta un impulso incondicionado que Arendt compara a un nacimiento. Dice nuestra autora: «Actuar significa tomar una iniciativa, comenzar (...), poner algo en movimiento. Este comienzo no es el mismo que el del mundo; no es el comienzo de algo, sino de alguien que es un principiante por sí mismo» ${ }^{37}$. Cuando hablamos de la acción, hablamos por tanto del inicio de algo nuevo que ningún conocimiento es capaz de prever ni predecir al punto que Arendt lo asemeja a un milagro: del hombre cabe esperarse lo inesperado, lo imprevisible, lo novedoso. «Con cada nuevo nacimiento nace al mundo un nuevo inicio y también un nuevo mundo entra potencialmente en el sen ${ }^{38}$. He allí la razón del profundo temor que despertaba la acción en los gobiernos totalitarios que intentaban a través del terror eliminar cualquier evento imprevisto e incontrolable.

Un sujeto que se revela a través de la palabra y de la acción no es un qué, sino un quién, una realidad única e irrepetible que hace su aparición en el mundo. En la medida que lo que revela no es algo, esto es, una realidad que puede objetivar y dominar, sería impropio hablar de un autor. Incluso se puede decir que la luz en la que vive la acción está oculta al agente, de modo que si la revelación puede presentarse de modo claro a los otros puede permanecer en la oscuridad a la propia persona. De esta revelación se pueden hacer posteriormente historias y narraciones, se puede configurar y delimitar el quién a través de monumentos y obras de arte, pero jamás se podrá repetir el momento mismo de este acontecimiento que se realiza en el aquí y ahora de la existencia. Es precisamente esta dimensión oculta a la vista aquello que rompe con la trama de la historia y de la sociedad, y la que permite que el hombre trascienda el mundo creado por él. La soledad y la

\footnotetext{
$36 \quad$ Ibíd., 222.

37 Ibíd., 205.

38 H. ARENDT: "De la naturaleza del totalitarismo", en ibíd., Ensayos de comprensión 1930-1954, 412.
} 
discontinuidad portan una positividad que coincide con el hecho mismo de existir y de estar en el mundo. Una positividad que no significa «una torre de marfil», sino una realidad singular abierta a la pluralidad.

\section{Conclusión}

El fin de la tradición, sellado dramáticamente a través de los regímenes totalitarios, significó para Arendt el fin de las categorías filosóficas y políticas que habían servido para interpretar la vida individual y social en occidente. En este contexto de quiebra del sentido común se hacía comprensible el rechazo de Arendt a ser parte de una tradición - la filosófica- que asumía como objetivo la contemplación de la verdad, esto es, la visión de una realidad trascendente a la vida de los hombres. Si el quehacer filosófico todavía es viable, lo será desde un inicio inédito que permita al filósofo tomar parte en la comunidad, insertarse con más intensidad en la vida de los hombres y familiarizarse con sus opiniones. Éste fue el camino que inauguró Sócrates a través de su intento de crear una comunidad de amigos desde la doxa, esto es, desde la comprensión del mundo «tal como se me presenta». El «conócete a ti mismo» del templo de Delfos era un llamado a aceptar nuestra condición humana, a abandonar todo intento de alcanzar una verdad absoluta ajena a los hombres. Significaba en pocas palabras esto: «la verdad absoluta e inmutable, trascendente a todo lo que existe, no está a tu alcance. Como ser humano no tienes la verdad acerca de todas las cosas. $\mathrm{Si}$ quieres conocerla, empieza preguntando». La única condición de la dialegesthai socrática del preguntar y responder es no caer en contradicción, es decir, no estar en desacuerdo consigo mismo. El temor a la contradicción nos revela que a pesar de estar solo, yo estoy en relación conmigo mismo y aparezco ante mí mismo. Esta relacionalidad originaria tendrá consecuencias importantes en la redefinición de la filosofía. En efecto, el thaumadzein no será comprendido más como el asombro ante una realidad que lleva al filósofo a desentenderse de la realidad política, como acontece en la alegoría de la caverna. La verdad no se opone a la doxa en la medida que el asombro entraña una relación y un ámbito de aparición. Tras el thaumadzein, Sócrates, lejos de apartarse de sus semejantes, se acerca a ellos para preguntarles, para familiarizarse con su doxa, para comprender el modo singular como el mundo se le revela a cada uno. En este sentido, La condición bumana de 1958 representa el intento de Arendt de redefinir el quehacer filosófico y superar la vieja hostilidad entre la filosofía y la política. Las nociones allí desarrolladas de igualdad, pluralidad, libertad y natalidad, apuntan a explicitar el carácter 
contingente y plural del hombre, alejándose de cualquier intento platonizante de definir a éste en términos de absolutez e inmutabilidad.

Sumario: 1. Ruptura con la tradición; 2. La defensa de la doxa; 3. La posibilidad de una nueva filosofía política; 3.1. Igualdad y pluralidad; 3.2. Libertad y natalidad; Conclusión. 